\title{
The role of electronic human resource management in diverse workforce efficiency
}

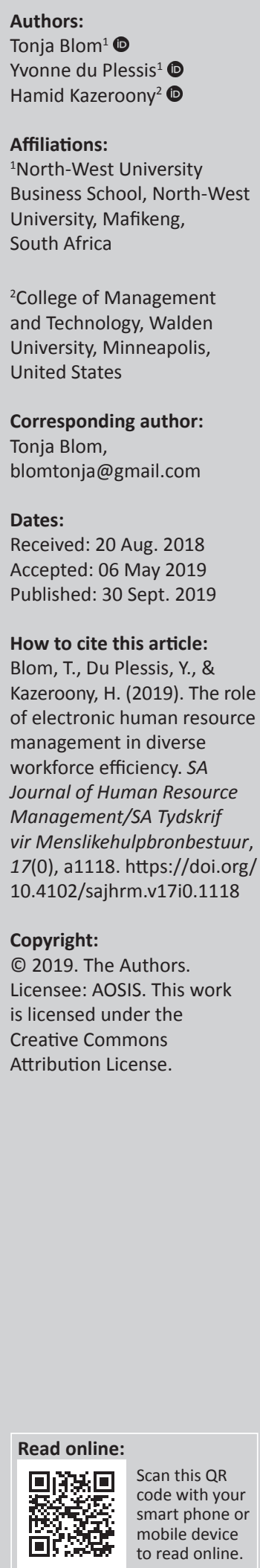

Orientation: Diversity management, focusing on developing and appreciating diverse ideas and building relations among diverse employees, and new electronic human resource management (e-HRM) approaches to employees, often leave employees feeling disrespected and indignant. Thus, instead of human resource practitioners, harnessing the strategic role of e-HRM towards value creation for people and organisation, e-HRM has taken a dehumanising turn.

Research purpose: This research questioned how technological changes affecting e-HRM could optimise and enable diversity.

Motivation for the study: Current literature does not adequately address this e-HRM dilemma impacting on HRM.

Research approach/design and method: A qualitative exploratory case study was used to determine how and to what extent the application of e-HRM technology implementation impacted on diversity management. The human niche and ecological model theories help explain the nature of employees' interactional relationships and coping mechanisms when intervening factors such as e-HRM are introduced respectively.

Main findings: The research revealed disconnectedness between e-HRM, individuals and groups, affecting efficiency. Further research is required to improve humanistic approaches for e-HRM implementations.

Practical/managerial implications: Application of human niche theory may guide a more participative approach from the onset. Leaders and managers who follow a pure transactional approach may fuel employee isolationism and hamper diversity management through technology in e-HRM.

Contribution/value-add: Our findings provide insight into the unintended consequences of diversity. We indicated how e-HRM systems can lead to relational breakdown in a developing country context. Technology should be integrated in managing diversity, and not just focused on operational efficiencies.

Keywords: ecological model; e-HRM; globalisation; human niche theory; humanistic; human resource management; diversity; technology integration; psychological reactance.

\section{Introduction}

Globalisation has resulted in the development of large, ever expanding, multinational organisations. Such organisations, operating in a global, competitive environment, utilise technological processes to drive improved efficiency. Complexities such as national regulatory requirements, diverse workforces and recognition of human dignity provide the rationale for human resource professionals and leaders to seek ways through which to improve diversity management. As a result, human activities and traditional human resource management (HRM) processes are being replaced with technology in electronic human resource management (e-HRM). Increasing dependence on technology to interact, communicate and collaborate has resulted in the creation of a faceless environment. Electronic human resource management challenges the concept of interpersonal relationship building in organisations, especially where diverse employee groups have to operate together. Therefore, organisations are tasked to rethink diversity management, in particular to maintain interpersonal relationships and organisational cohesion.

This research was performed in a multinational organisation. The parent organisation expected all affiliates to conform to global standards through similar operations. Within this multinational organisation, human resources (HR), specifically e-HRM, was utilised as a tool to 
ensure standardisation across country boundaries. The researched organisation employed a diverse workforce. Gender, ethnicity, race, colour, language, culture, religion and education contributed to the compilation of the diverse workforce. As diversity is a key concept of this research and represents a kaleidoscope of difference along a continuum (Beck \& Cowen, 1996) which can be explained from multiple perspectives. D'Netto, Smith, Da-Gama-Pinto and Dima (2000, p. 78) described diversity as the differences 'of race, ethnicity, gender, culture, age, sexual orientation, religion, language, socio-economic status, education, style, personality, family status, physical and mental ability'.

\section{Research purpose and objectives}

Technology plays a significant role in changing the way organisations work (Deloitte, 2014) and dramatically impacts on the practice of human resources, and its influence is rapidly increasing (Johnson, Lukaszewski, \& Stone, 2017). The success of e-HRM largely depends on effective interactions between people and computers (Gueutal \& Stone, 2005). Many large multinational organisations have adopted e-HRM, making technology central to HR practices (e.g. Kavanagh, Thite, \& Johnson, 2015; Stone, Deadrick, Lukaszewski, \& Johnson, 2015; Strohmeier, 2007). For more than four decades, organisations have implemented e-HRM technology in the hope of achieving administrative and strategic benefits (Marler \& Parry, 2016). Unfortunately, e-HRM projects continue to report failures (Martin \& Reddington, 2010; Smale \& Heikkilä, 2009; Tansley, Newell, \& Williams, 2001) and achieve less than expected results (Chapman \& Webster, 2003).

Despite the existence of recent reviews of e-HRM, Bondarouk, Parry and Furtmueller (2017) state that we still lack a comprehensive understanding of factors affecting the consequences of e-HRM. Bondarouk et al. (2017) found that technology, organisation and people affect the adoption of e-HRM. The resultant consequences of e-HRM relate to operational, relational and transformational processes (Bondarouk et al., 2017).

Studies showed that HR professionals were unsuccessful in using technology to initiate and support strategic decisions (e.g. Dery \& Wailes, 2005; Marler \& Parry, 2016). Human resource professionals primarily used e-HRM technology to simply support routine administrative HR tasks (Ball, 2001; Haines \& Lafleur, 2008; Hussain, Wallace, \& Cornelius, 2007). Line managers reported contradictory results when using e-HRM (Reddington \& Hyde, 2008). The potential of e-HRM was constrained by the complexities of people dynamics such as managing user acceptance when adapting new e-HRM systems (Grant et al., 2009). The integration of HR technologies into organisational processes, such as recruitment and performance management and development, also failed to deliver on its promise of providing a positive solution for identifying the right human attributes with respect to diversity (Kuhn \& Skuterud, 2000; McManus \& Ferguson, 2003; Zusman \& Landis, 2002).
Generally, through globalisation, societies have been influenced by European and American cultures (Ogihara \& Uchida, 2014) to accept technology integration into HR processes. These e-learnings range from providing training material to advanced content delivery (Johnson \& Brown, 2017). Sitzmann, Kraiger, Stewart and Wisher (2006) found well-designed Web-based training as effective as face-to-face training; however, designers must consider both student and instructor characteristics, communication, learner control and technology design (Johnson \& Brown, 2017). Conversely, training performance has been found to suffer when systems are complex and challenging to use (Alavi, Marakas, \& Yoo, 2002).

A deeper understanding of human-computer interface design principles may enhance the effectiveness of e-learning (Johnson et al., 2017), as students struggle to analyse complex data when delivered through mobile-learning (m-learning) (Kaganer, Giordano, Brion, \& Tortoriello, 2013). It has been argued that the use of games in e-learning increases motivation and learning (Salas, DeRouin, \& Littrell, 2005). Other research suggests reduced satisfaction and engagement (Foster, Sheridan, Irish, \& Frost, 2012).

Little focus has been placed on how technology design and human-computer interface issues affect HR outcomes (Johnson et al., 2017). This has fuelled employee isolationism and led to transactional, rather than relational HR practices (Stone et al., 2015). Specifically, diversity management and new e-HRM approaches have taken a dehumanising turn (Stebbins, 1989), leading to employees' resistance (Cummings \& Worley, 2005; Senior \& Swailes, 2010), alienation and mistrust of e-HRM which has not been addressed adequately in current literature (Francis, Parkes, \& Reddington, 2014).

The above outline of the research problem led to the formulation of the following research question:

How can organisations optimise and enable diversity management through technological change, as opposed to remaining only a process-driven, functional and transactional technological implementation? The purpose of this article is to offer an answer to this question. The remainder of this article is structured as follows in order for it to achieve its aim. The next section contains the conceptual-theoretical framework against which the research was performed, followed by a report on the empirical investigation that was launched based on this framework. Thereafter the findings and contribution are discussed.

\section{Literature review}

As technology is integrated into the workplace and cultural diversity takes root as a global phenomenon, examining effective diversity management becomes imperative. Organisations can benefit from appropriate implementation of diversity in the highly evolved technologically oriented workplace (Zanoni, 2011) without becoming overly 
functionalistic (Varey, Wood-Harper, \& Wood, 2002) or dehumanising individuals (Stebbins, 1989).

\section{Technology integration in human resource management (electronic human resource management)}

Electronic-based HRM, labelled e-HRM (Strohmeier, 2007), allows an entire business to be run from your computer or smartphone to support quick, data-driven decisions and performance management (Marler \& Parry, 2016) - without face-to-face employee contact. According to Bondarouk and Ruël (2009), the term e-HRM covers all HR and technology integration mechanisms with the aim of creating value. Electronic human resource management has been defined as a set of technology configurations that enable HRM activities through coordinating and controlling data, information and communication within and across organisational boundaries (Marler \& Parry, 2016).

Technological changes to systems and processes are often undertaken from within an engineering or functionalist paradigm (Varey et al., 2002). Functionalist approaches are popular, widely accepted (Samoilenko, 2008) and implemented with a fair amount of success (Fitzgerald, 1997) as they promise consistent performance outcomes (Patnayakuni, Ruppel, \& Rai, 2006). However, functionalist approaches often fail or underperform (Doherty \& King, 2001; Truex, Baskerville, \& Travis, 2000; Wynekoop \& Russo, 1995), and rigid adherence leads to dysfunctional technology application (Chatterjee, Sarker, \& Fuller, 2009). This paradigm often views technology as a substitute or replacement that questions (Harmon, Korn, Light, \& Voida, 2016) and disrupts (Horney, 2016) the status quo. As an emotional experience, this translates into a process of loss (Kübler-Ross, 1963).

System success and failure is a direct consequence of the effectiveness of collaborative change management processes, which aim to mitigate the disruptive effects of system adoption (Dwivedi et al., 2015). Most often, this takes place in a complex business environment (Bunker, Levine, \& Woody, 2013). This highlights the importance of contextual understanding (Dwivedi et al., 2015) as technology implementation involves more than just getting information technology artefacts to run (Myers, 1994). Within a change management context, Blom (2015) builds on Lewin's (1951) three-step model, adding the importance of unfreezing, change and refreezing as a technical requirement but also as a people requirement. Sherer, Kohli and Baron (2003) argue that technological success (and failure) is a direct consequence of the effectiveness of change management processes that mitigate the disruptive effects of technology implementation. Effective change management is dependent on the identification of key issues that impede multiple and diverse organisational stakeholder engagement (Sherer et al., 2003).

Technological implementation changes the way employees work and think, resulting in political changes, some people win and some lose (Orlikowski \& Robey, 1991). Digital technologies such as e-HRM often reflect adverse consequences for employees (Spencer, 2017). Integrating technology into HR has been influenced by stakeholder satisfaction and cost effectiveness (Afiouni, Karam, \& El-Hajj 2012; Briscoe, Schuler, \& Claus, 2009; Reilly \& Williams 2003; Stahl, Mendenhall, \& Oddou, 2012). This presents challenges for HR transformation (Stone \& Deadrick, 2015) such as reduced creativity and increased team diversity (Egan, 2005), individual stress based on the concern for job loss (Gowan, 2012) and lack of sufficient attention to individuals' needs for dignity and life balance (Cleveland, Zinta, \& Cavanagh, 2015).

In the context of the research performed, employees reported in the focus group sessions that they did not appreciate being treated like robots and numbers. In these sessions, employees said they felt disrespected, indignant and dehumanised. Also, that employees did not take kindly to the transference of such a mechanistic culture driven by technology. The case study revealed that the top-performing group leaders were chosen to showcase the validity of this technological change initiative.

The extent of e-HRM on a socio-emotional level in African contexts has not been researched. Sykes (2015) laments the fact that despite progress in understanding the benefits of such integrated systems, little is known about support structures used to help employees' cope with technology implementations. Farndale, Paauwe and Hoeksema (2009) suggest that technology has the potential to create organisational change, but that such change must be enacted by managers and employees.

We argue that the aim of e-HRM is to streamline processes which require people and technology to interact. As the socio-emotional impact of a faceless HR without relevant support structures is unclear and as e-HRM threatens individual and group freedom, it becomes difficult to realise this aim.

\section{Globalisation and strategic human resource}

Globalisation is an important construct even though there is no one recognised definition for globalisation (Choo, Halim, \& Keng-Howe, 2010). The meaning differs depending on the doctrine (Barnum \& Wolniansky, 1989). However, researchers agree that globalisation caused growing economic interdependence which affects individuals, business, industry and country (Garrett, 2000; Govindarajan \& Gupta, 2001; Thoumrungroje \& Tansuhaj, 2004).

Human resource represents a key strategic resource (Boudreau \& Ramstad, 1998) and HRM is critical to organisational success (Barnes \& Adam, 2017). Therefore, HR evolved into a strategic business partner (Choo et al., 2010; Garg \& Goel, 2016) with deliverable objectives (Wan, Kok, \& Ong, 2002). This has propelled HR in a new direction (Stone \& Deadrick, 2015). European and American influence (Ogihara \& Uchida, 2014) led to transactional, rather than relational HR practices (Stone et al., 2015). Today, the HR department must replace traditional 
HR practices for transformational practices to realise a tangible competitive advantage (Lepak \& Snell, 1998; Lepak, Bartol, \& Erhardt, 2005).

Globalisation requires that organisations move away from outdated HR practices. However, it seems that HR has lost the way among transactional, relational, transformation and electronic paths. Of concern though is that new practices could be potentially harmful while still not realising the ideal of streamlined processes.

\section{Psychological reactance theory}

This technological change was heavily resisted. Resistance largely contributed to project failure. Although resistance to change is a recurring theme in the literature (e.g. Cummings \& Worley, 2005; Senior \& Swailes, 2010), organisations appear to be helpless in the face of rife resistance. Fear and threat, whether elicited by anger or as a coping behaviour for fear (e.g. Ivanov, Pfau, \& Parker, 2009; Lee \& Pfau, 1998; Pfau et al., 2010), may heighten the desire to protect attitudes, especially if those attitudes are deemed important or relevant (Miller \& Averbeck, in press). Such a heightened state of motivation enhances resistance (Miller et al., 2013).

Psychological reactance is an aversive affective reaction in response to rules and regulations that impinge on freedom and autonomy (Brehm, 1966, 1972; Brehm \& Brehm, 1981; Wicklund, 1974). This reaction is common when individuals are forced to engage in specific behaviour. A perceived diminution in freedom ignites an emotional state, called psychological reactance which elicits behaviours that are intended to restore this autonomy (Brehm, 1966, 1972; Brehm \& Brehm, 1981; Wicklund, 1974).

Reactance is experienced whenever a free behaviour is restricted (Brehm, 1966, 1972; Brehm \& Brehm, 1981; Wicklund, 1974). Dogmatic messages are perceived as threatening while less dogmatic messages result in less negative reactions (Quick \& Stephenson, 2008). The physical characteristics of an environment can also provoke a form of reactance (Levav \& Zhu, 2009). The motivation of reactance is to re-establish freedom. This motivation could be unconscious. Reactance can provoke behaviours that oppose the rules or course of action that were imposed and encouraged (Buller, Borland, \& Burgoon, 1998).

Within this research, context, fear and anger as well as uncertainty largely contributed towards resistance. Dogmatic communication aggravated resistance and fuelled the desire to re-establish perceived freedoms.

\section{Diversity, inclusion and human resource theories}

In addition to the diversity definition given above, diversity also relates to social, psychological and demographic differences in background, income, marital status, religious beliefs, experiences, perspectives and status within the organisational hierarchy (e.g. Cox, 1993; Jackson \& Ruderman, 1996; Loden, Rosener, \& Rosener, 1991). Diversity management is defined as initiatives that can increase commitments, interaction, performance and creativity by individuals (Ivancevich \& Gilbert, 2000) as individuals feel included in the organisation (Mor Barak, 2015). For this article, diversity is defined as differences and similarities with respect to gender, race, ethnicity, psychological frame, culture and world view.

Human resource theories have been developed based on European American assumptions about the cultural values of homogeneous individuals in organisations (Gelfand, Erez, \& Aycan, 2007; Stone \& Deadrick, 2015). Gollner, Andersen, Gollner and Webster (2015) emphasise the importance of assessing cultural dynamics when integrating technology. In the South African context, elements of individualism and collectivism are practiced by various cultural groups (Van Dyk \& De Kock, 2004) and are likely to have various economic effects (Gorodnichenko \& Roland, 2011).

Given growing diversity in organisations, creating inclusive environments becomes important (Nishii \& Rich, 2014). Nishii (2013, p. 1754) states: 'In inclusive environments, individuals of all backgrounds-not just members of historically powerful identity groups are fairly treated, valued for who they are, and included in core decision making'. According to Mor Barak and Daya (2014):

$[A] n$ exclusionary workplace is based on the perception that all workers need to conform to pre-established organizational values and norms (determined by its 'mainstream'), the inclusive workplace is based on a pluralistic value frame that respects all cultural perspectives represented among its employees. (pp. 393-394)

Inclusion involves equal opportunity for members of socially marginalised groups, thus allowing all to participate and contribute while providing opportunities and support for members of non-marginalised groups, permitting full engagement at all levels of the organisation as well as being authentically themselves.

Within this multinational and diverse organisation in South Africa, utilising diversity markers such as gender, race, ethnicity, culture, religion, language and education could potentially exclude and divide, thereby resulting in detrimental economic outcomes. In an attempt to move away from such diversity markers, we turned to ecological and human niche theory.

\section{Ecological and human niche theory}

General system's theory (Bertalanffy, 1973) influenced Haeckel's 1868 ecological theory (Naess, 1989) which explains the interaction of organisms with the environment and their interdependencies. As touched on earlier, Lewin (1951) took a psychological perspective, demonstrating that a person's behaviour is the function of their interaction with the environment. Bookchin (1980) sought a non-hierarchical society where human beings, without gender, race and class categorisation, could live interdependently without environmental domination. 
Naess (1989) argued that the complexity and diversity of the ecosystem protects it from destruction. Human niche theory unfolds the nature of interaction and adaptation of the organism and environment. It describes how organisations create social spaces, providing access to resources, determining the nature of the interaction between organisms and organisations and allowing for organisms' adaptability as organisations change (Putnam \& Archibald, 2016). Palmer, Coe and Steadman (2016) included social in the human niche theory, addressing the evolution of organisms' successive generations, in an environment built on the previous mental models, expanding the relationships and interactions, creating new homeostasis (Palmer et al., 2016).

Human niche theory (Laubscher, 2013) extends Graves's (1974) double-helix system which emphasises questions of existence and coping mechanisms. Helix I represents internal (e.g. genetic make-up, inherited characteristics, tendencies and native intelligences) and external (the social and physical factors impinging on the individual or group that define the context in which choices are made) conditions of existence. Helix II represents coping methods, displayed as attitudes and behaviours in response to 'why' questions.

Laubscher (2013) believes that $65 \%$ of people in Africa belong to a human niche which has the capacity to connect and form groups. Identity is defined in the interrelatedness with each other and self is not identified as a separate entity, but in relation to the collective. Such individuals will sacrifice the self for the group. Here, the group is typically organised in a circular form. Organisations are complex systems and technology, not integrated into the relevant collective system, further ads to the complexity.

Answering existentialistic questions with interrelated awareness (human niche theory) and realising the impact of environmental interaction (ecological theory) on behaviour may shed light on how technology may be utilised in HR systems to optimise workplace diversity. It seems that more 'human sensitive' HR systems are called for when technological expansion is required. Being mindful of the psycho-social impact of technology in a diverse society, acknowledging the significance of multiple elements such as a diverse workforce and African cultural dynamics may improve technology integration when integrated into a coherent wholeness. This may also ring true for Middle Eastern, Asian and American cultural dynamics; however, this case relates to South Africa as part of the African continent.

\section{Case study}

The backdrop of this case study was the motor manufacturing industry in South Africa. Initial cost justifications were performed in 2008, and again in 2009 and 2010. The project commenced in 2011, in a large, process-driven and authoritarian manufacturing company ( $N=5256$ employees) in South Africa. This company had a diverse employment composition. Employees embarked upon a total working time (TWT) technological system implementation to enable the measurement and improvement of labour efficiency. The workforce comprised different genders, age groups, cultural groups and levels of education.

At the onset of the project, man-hour-per-unit (MHU) was used as an efficiency measurement tool and based on an ideal situation, assuming that every employee spends $7.58 \mathrm{~h}$ working. Such timing is unrealistic given nature breaks, training and medical station visits. Utilising an inaccurate MHU resulted in incorrect labour allocations, which affected wages. A more accurate calculation was needed to ensure optimal labour allocation. This radical change initiative and standard implementation would enable management to have real-time data available for decision-making at the touch of a button. The data would account for every minute of the employee's time spent while in the production facility. Such data would assist agile decision-making in the global arena. The project did not consider and account for the sensitive nature of the data, the impact on the human psyche when under constant observation and the possible implication when the take-home-wage is affected.

The change initiative involved four manufacturing plants and required change from the lowest levels of employees to senior managers and impacted five hierarchical levels. A further three upper hierarchical levels would utilise the collected data for strategic planning, human resource decisions, pay allocation, costing and supply chain decisions. To illustrate, a senior manager would have numerous reporting section managers. Group leaders would report to one section manager. Group leaders are responsible for several team leaders who, in turn, are responsible for various team members. Team member, team leader and group leader activities would be monitored to determine time spent away from the production line. This data would then be utilised for high-level decision-making such as (1) hourly pay, (2) parts costs and (3) number of labourers required in each production process.

To realise this technological change implementation, the objectives were: (1) exposing and quantifying inefficiencies that effect actual TWT, (2) designing a system to capture and track actual TWT across all plants, (3) achieving optimal labour allocation through a true MHU calculation and (4) determining the average time per part assembly. This change would completely alter working data factors. The successful deployment, implementation and daily use of this new system would thus depend on the co-operation of the diverse workforce.

Breaking down the project-specific male or female demographics indicates a dominant male profile (85\%) which is true in most manufacturing plants in South Africa. Structurally, team members report to team leaders and team leaders, in turn, report to group leaders.

The group leaders affected were $N=224$. These group leaders were shadowed by their international counterparts. This meant that, on a daily basis, group leaders were followed, 
observed, taught and monitored throughout the production process by a foreigner. Their international counterparts all spoke a different language and constituted a homogenous group.

This technological change required daily capturing by group leaders. The amount of time spent by every team leader and team member had to be captured. The amount of time spent was to be indicated as absent, early out, late in, quality, training and/or time spent in the medical facility. Initial investigation indicated that less than half of the group leaders had previous experience in and training on using a personal computer. Thus, group leader computer training was added to the project plan and resulted in a secondary project.

A top-down communication approach was followed which filtered information through the many hierarchical levels. Time and attendance, absenteeism, leave and general work methods are governed through this hierarchy. Similarly, punitive action because of non-compliance is meted out through this hierarchy.

Given the large number of employees involved, the communication function resided with the general manager of each production area. The top-down line of communication followed the organisational hierarchy from general manager to senior manager, from section managers to group leaders and from team leaders to team members. Ensuring correct communication through such a long line of communication proved challenging. Many employees felt that information was shared on a need-to-know basis. Rumours were common and employees on the production line became withdrawn, quiet, inhibited and unresponsive.

\section{Research design Research aim}

The aim of the investigation was to explore how and to what extent technological change was implemented in a diverse, multicultural organisation.

\section{Research design, strategy and method}

The research was qualitative, utilising an exploratory case study design and content analysis. Data collection was performed through in-depth semi-structured interviews, focus group sessions, solicited company data, field notes and observations. The in-depth semi-structured interviews aimed to understand the concept of technological change as viewed by senior management. The focus groups explored the impact of technological change on employee performance. Minutes and project work documents were utilised to contextualise transactional work processes and the impact thereof on work performance. Observations in the workplace of employees' behaviours and activities provided understanding of employee engagement (or not), productivity, attitude and work behaviour in relation to the technological change.

\section{Data collection}

Eight in-depth semi-structured interviews were led with senior managers. Each of the four focus group sessions comprised seven employees from middle and senior management. Four focus group sessions were led. Participants were selected based on the relevance of their involvement in the technological change project. Therefore, all participants were directly involved in the execution of strategic change initiatives. Theoretical sampling was employed to identify subsequent participants and to add sources as the research progressed.

The in-depth semi-structured interviews lasted between 60 and $90 \mathrm{~min}$ and were recorded. The researcher took notes during the interviews, jotting down prominent issues, subjects and areas of focus. The interviews were transcribed within 5 days of the interview. A memo was written subsequent to each interview. If required, a follow-up meeting with the participant was arranged to ensure correctness and to clarify any items which required further elaboration.

Focus group sessions were conducted utilising a semistructured discussion format. Questions were asked and participants were free to engage (or not) with other group members. The focus group sessions mixed participants from various departments. The focus group sessions lasted between 50 minutes and 60 minutes and were recorded. These sessions were transcribed within 5 days. A memo on the prominent issues and focus areas was written subsequent to each focus group session. If required, a follow-up meeting was arranged to ensure correctness and to clarify any items which required further elaboration.

\section{Data analysis}

Comparative content analysis (Neuendorf, 2002) was used to systematically analyse the data transcriptions. Concepts related to the research question were identified. A classification scheme was developed from the concepts to produce categories. An example of categories is displayed in Table 1, indicating the contributing participant against concepts such as inclusivity, participation, resistance, stress and disempowerment. Relational maps were drawn to assist with linkages between concepts. An example of such a map is displayed in Figure 1.

The classification scheme was continually compared and reworked (Berg, 1998) through continued, line-by-line searches for similar and distinct concepts. Emerging patterns

\begin{tabular}{|c|c|c|}
\hline No. & Category & Participant identity code \\
\hline 1 & Inclusivity & $\mathrm{F} 4, \mathrm{~F} 2, \mathrm{P} 20, \mathrm{P} 17, \mathrm{P} 2, \mathrm{P} 4, \mathrm{P} 5$ \\
\hline 2 & Participation & $\mathrm{F} 4, \mathrm{~F} 2, \mathrm{~F} 3, \mathrm{~F} 1, \mathrm{C} 1, \mathrm{C} 2, \mathrm{C} 3$ \\
\hline 3 & Resistance & $\mathrm{F} 3, \mathrm{~F} 1, \mathrm{~F} 2, \mathrm{~F} 4, \mathrm{P} 20, \mathrm{P} 17, \mathrm{P} 4, \mathrm{P} 5, \mathrm{P} 1, \mathrm{P} 2, \mathrm{C} 1, \mathrm{C} 2$ \\
\hline 4 & Stress & $F 4, F 1, F 3, F 2, P 20, P 17, P 4, P 5, P 2, P 3, C 1, C 2, C 3$ \\
\hline 5 & Disempowerment & $\mathrm{F} 1, \mathrm{~F} 2, \mathrm{~F} 4, \mathrm{~F} 3, \mathrm{C} 1, \mathrm{C} 2, \mathrm{C} 3$ \\
\hline 6 & Demotivated & $\mathrm{F} 2, \mathrm{~F} 1, \mathrm{~F} 3, \mathrm{~F} 4, \mathrm{C} 1, \mathrm{C} 2, \mathrm{C} 3$ \\
\hline
\end{tabular}




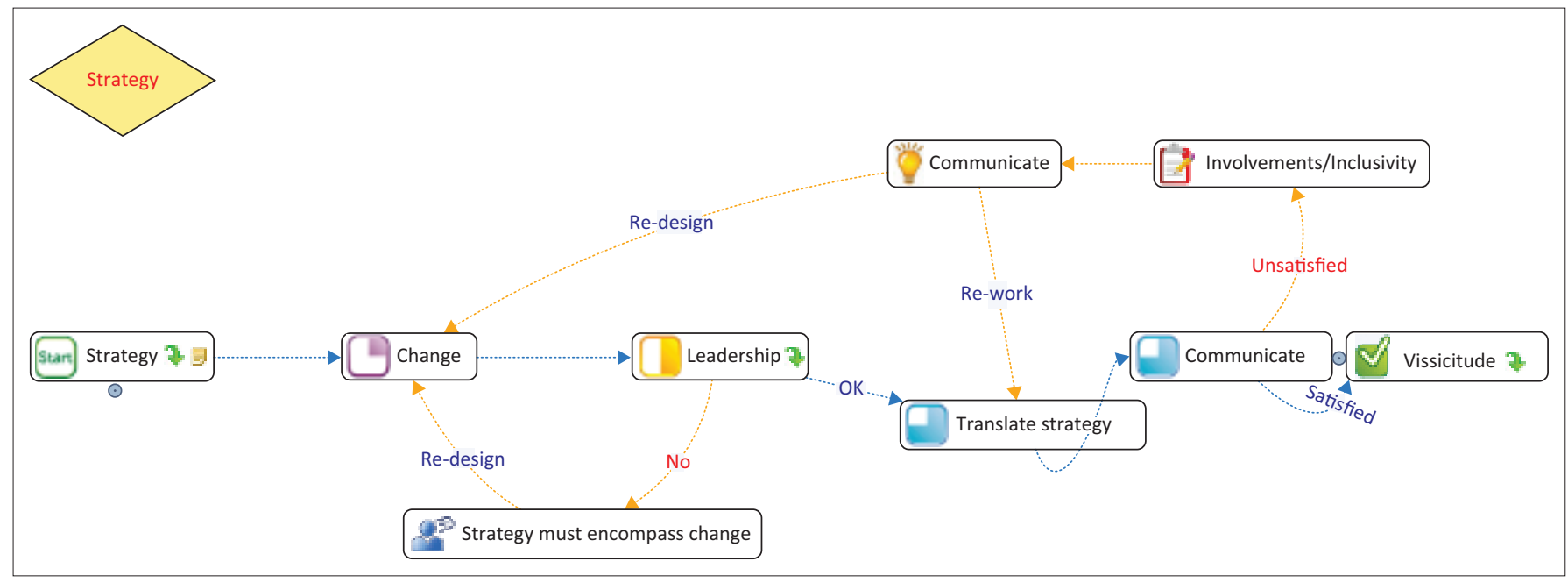

FIGURE 1: Relational map example.

were reviewed to confirm understanding based on the results (Patton, 2015). Concepts were developed into themes and sub-themes which were linked to theory.

The research attempted not to simplify what was observed. Special efforts were made to recognise the multifaceted dimensions relating to technological change and diversity. The multiple sources of data gathering illuminated the research from different angles. Quality data were ensured through trustworthiness dependability, confirmability, replicability and transferability

\section{Ethical considerations}

Ethical clearance and approval to perform research was obtained from the School of Business Leaders, University of South Africa. All participants gave informed consent. Confidentiality and anonymity were ensured. Prior to the focus group sessions, the names of participants were shared with other participants. This was performed to ensure that all parties were comfortable to share in the focus group sessions. It was repeatedly stated that participation was voluntary and withdrawal from the process was possible at any time.

\section{Findings \\ Technology integration}

The findings confirmed that e-HRM was implemented in this particular organisation to streamline HRM processes in order to improve competitiveness. Also, that e-HRM will probably not be implemented successfully if people and technology fail to interact with each other. This case confirmed the findings of Varey et al. (2002) who stated that technology changes are often undertaken from within an engineering or functionalist paradigm. Further, that such an approach is primarily undertaken to ensure consistent performance outcomes. Also that such a functionalist paradigm more often than not fails or underperforms and that rigid adherence to functional principles leads to dysfunctional technology application.
Typical responses towards this technological implementation were:

'Profits are more important than people.' (F1.1, female, middle manager)

'Organisations are firstly concerned about profits.' (F1.2, male, middle manager)

'The aim of change is to improve profit.' (F2.3, female, senior manager)

\section{Globalisation}

The role of HRM in contemporary competitive industry is critical to organisational success and the belief that an organisation's human capital represents a key strategic resource is accepted. Also, that HR has evolved to a strategic business partner. However, from an employee's perspective, the following was said:

'No process regarding the impact of business change.' (P1, male, CEO [chief executive officer])

'Strategy does not encompass change.' (P1, male, CEO)

'Strategic plans on change are non-existent.' (P4, female, Snr management)

'Senior staff [have] no strategic plans for change.' (P5, male, CEO) 'There is no strategy for change.' (P1, male, CEO) 'Strategy should encompass change, but it does not.' (P1, male, $\mathrm{CEO}$ )

'The future of the organisation is in the hands of the employees.' (P1, male, CEO)

'Empowerment is not understood.' (P17, male, Snr management) 'We must empower people during change. We don't.' (P17, male, Snr management)

Regarding HR and the role of HR in change, the following summarises typical responses:

'There is no planning for change and everybody think[s] they are change managers.' (P17, male, Snr [senior] management)

'No change knowledge can cause harm.' (F1.1, female, middle management)

'Managers don't have change knowledge which makes change worse.' (F1.4, female, middle management)

'... ashamed of what change managers do.' (F2.5, male, middle management)

'Not everybody in HR can do change. HR often does not help change.' (F1.3, female, middle management) 


\section{Psychological reactance theory}

Employees who were integral to the project's success heavily resisted this project. The technological implementation threatened the freedom of employees who were responsible for data capturing. As such, employees refused to capture data as they felt watched. The traumatic nature of the project resulted in employees' feeling uncertain, disempowered and fearful.

Reactance was experienced whenever a free behaviour was restricted or monitored. As rigidity increased, the perceived threat increased, resulting in serious resistance. Employee reactions confirmed the above:

'No buy-in will result in resistance.' (P17, male, Snr management) 'Different messages create fear. Uncertainty creates fear.' (F1.1, female, middle management)

'Stress plays a huge role.' (F4.1, female, middle management)

'Employees operate from a fear perspective.' (F3.2, male, middle management)

'Employees' first reaction to change is fear. Their second reaction is scepticism. Is this change really required?' (F3.5, male, middle management)

'Management must convince people to participate in change and potentially lose their job. Change impacts on the individual.' (F2.2, male, middle management)

Responses illustrated how fear, anger and anxiety harmed employees:

'People who trust your leadership might lose their jobs.' (F3.2, male, management)

'Change is very traumatic.' (F4.5, female, middle management)

'All should benefit through the change. This does not always happen.' (F3.2, male, middle management)

'Employees must be involved'. 'Involvement improves acceptance.' (F2.4, male, middle management)

'Involvement makes implementation easier. Involvement improves buy-in. Involvement means change.' (F2.4, male, middle management)

'Poor communication worsened my resistance.' (F1.1, female, middle management)

'I felt helpless because nobody explained the change'. '... [I] resisted as a result of a loss of autonomy.' (F4.2, male, middle management)

'I resisted because I did not understand why'. ' ... resistant to the process.' (F1.1, female, middle management)

'My change attitude was negative.' (F4.5, female, middle management)

'I resisted because of past experiences.' (F3.6, female, middle management)

'I felt sceptic[al].' (P20, male, senior regional management)

'Reduced autonomy resulted in negativity.' (P4, female, senior management)

'Reduced autonomy results in change failure.' (P4, female, senior management)

'Change reduces autonomy.' (P4, female, senior management) 'No involvement, no participation.' (F2.1, male, middle management)

'Disempowerment'. 'Reduced autonomy.' (F3.4, male, middle management)

'... [I] don't know your employees. Idon't know their circumstances, but then I expect them to follow me.' (P1, male, CEO)
The responses of resisting employees could be summarised as:

'People don't know where they are expected to go. That's why they resist.' (F1.1, female, middle management)

'People are apprehensive and careful.' (P20, male, senior regional management)

'People don't' want to go to the uncertain. They rather stay with what they know.' (F4.6, male, middle management)

\section{Diversity}

The research outcomes revealed that older employees (elders) in the collective workgroups determine who does what (roles and responsibilities). This is contrary to organisational practice where work roles are determined by job descriptions. The elders perceived new technology as threatening to individuals and teams, and as extreme 'super'-vision. Different thinking processes were also at play during the implementation of this change. This technological change superseded diversity markers such as race, ethnicity and gender as different groups (management vs employees) displayed different ways of thinking about the change.

\section{Management perceived the change as:}

'Change preparation is important. It is important to show people what the change looks like, but we don't do it.' (P20, male, senior regional management)

'Organisations see where they are going to and then see if the change has what is needed. If not, further change is introduced.' (P1, male, CEO)

'Mechanistic planning happens to an extent.' (P1, male, CEO)

'Change is inevitable.' (F4.1, female, middle management)

'Positive change, the organisation will thrive. Negative change, the organisation will die.' (P1, male, CEO)

'Change will happen.' (P1, male, CEO)

Employees perceived the change as:

'Change is done roughly.' (F1.1, female, middle management)

'Deadlines are always missed'. 'There is no planning.' (F4.1, female, middle management)

'Lack of planning.' (F4.1, female, middle management)

'No schedule for changes.' (F4.1, female, middle management)

'Poor planning.' (F4.2, male, middle management)

'There is no change preparation.' (F4.2, male, middle management) 'Sometimes there is a plan, but the plan is never shared.' (F4.3, male, middle management)

'The organisation is mostly reactive to change.' (F4.3, male, middle management)

'Change was all over the show.' (F4.1, female, middle management)

'Change was very messy.' (F4.1, female, middle management)

'Excluded.' (F4.3, male, middle management)

'No one understands why.' (F4.3, male, middle management)

'Things are just done.' (F4.1, female, middle management)

'Management does not handle stress correctly.' (F4.1, female, middle management)

'Change is about empires, power games and then spending a lot of money on damage control in the end. It demotivates me.' (F4.1, female, middle management)

'I felt demotivated and disempowered.' (F4.2, male, middle management)

'I was not empowered to deal with the change.' (P4, female, senior management) 
'I was uninvolved.' (P4, female, senior management)

'I would have followed if I understood.' (F3.5, male, middle management)

'I have my way of thinking, but I did not understand the changes.' (F3.5, male, middle management)

\section{Ecological and human niche theory}

The case revealed the importance and impact of environmental interaction. Compliant employees became highly resistant as their interaction with the environment was challenged by technology. The power of the hierarchical system (both formal and informal) was also displayed:

'Communication is very difficult in a structured environment.' (P4, female, senior management)

'Middle management is a big obstacle to change.' (P5, male, CEO) 'Middle management obstructs change.' (P5, male, CEO)

'... implements non-workable solutions.' (F4.1, female, middle management)

'Management's ... narrow view ... instant gratification and power games ... creates disaster.' (F4.1, female, middle management)

The case also illustrated the relevance of human niche theory in a diverse setting. Native intelligences (via elders or informal structures) overruled management decisions. The social and physical factors determined how the group would oppose choices, thereby ensuring failure of the project. Further, as the group perceived to be threatened, an innate capacity to connect was exposed. Identity was sacrificed and vested back into the group - for cohesion, defence and protection. Management was placed into an opposing corner. From these divergent views, finding commonality becomes extremely difficult. The following verbatim responses were made towards management:

\footnotetext{
'... understand what motivates people.' (P13, male, senior regional manager)

'Management must show the end picture.' (P13, male, senior regional manager)

'Management must know their employees.' (P1, male, CEO)

'Management is not aware of people.' (P1, male, CEO)

'Management empowers the wrong people'. (F2.3, female, middle management)
}

Despite the fact that the organisation has an employee assistance programme, the following responses indicate a severe lack of support.

'Nobody cares about people's personal stress.' (F2.3, female, middle management)

'I felt stressed because of the uncertainty.' (F2.3, female, middle management)

'There was no help available.' (F1.1, female, middle management) 'The organisation does not know how to handle employee stress levels.' (F1.1, female, middle management)

'Organisations do not handle stress correctly, not even in stable times. More so during change.' (F2.4, male, middle management) 'Organisations pay lip service to stress.' (F1.11, female, middle management)

'... damage to people.' (F2.3, female, middle management)

'I don't want to come to work ...' (F2.3, female, middle management)

\section{Discussion Outline of results}

Our research revealed a multiple-level disconnect between e-HRM, organisation and employees (individuals and groups) because of mechanistic technology implementation. We characterised this disconnect as 'negative psycho-socio emotions' in play during the process of technological change implementation. Such disconnect increased feelings of stress, fear and anxiety, limiting individuals from fully engaging with the organisation. Furthermore, this disconnect seemed to be perpetuated by neglecting human diversity when implementing e-HRM to optimise business efficiency. This project was the antithesis of how change should be done given the drastic conversion in work methods. It can be equated to subjecting employees to constant surveillance, as if they are 'tracked by a device'. This severely infringes on personal privacy. No change management process was followed as change management was not viewed as important by the developing and implementation team, which is typical in mechanistic technology project implementation. Three years after commencement, the project was still not active and could therefore be classified as an attempted technological change that failed based on time, cost, quality and beneficial change delivery.

This project resulted in a lose-lose situation, in reduced creativity and increased individual stress. Given the lack of change management process, the disruptive effects of technology implementation could not be mitigated. The rigid adherence of a functionalist paradigm with overly functionalistic approaches resulted in human reactance and dysfunctional technology implication. An awareness of some of the discussed aspects could have assisted the organisation in harnessing key strategic resources, relational practices and increased competitive advance.

\section{Practical implications}

Theoretically, it seems as if we know exactly what to do and even how to do it, but are just not doing it. By utilising human niche theory, which respects diversity of people, success could have been achieved. Instead of assuming technology as an efficiency mechanism in all contexts and that people will just be able to perform through 'plug and play', much has to be understood about change implementation in general and technological change in particular in diverse cultural groupings.

Within an African context, application of human niche theory should have guided a more participative approach from the onset. Influential (elder) employees could have been involved as pivotal role players as opposed to employees with hierarchical or positional power. Circular discussion groups with such elders and employees, through a participative approach, could give opportunity to lower level employees to be part of the narrative. This narrative could have been shared through storytelling and/or an organisational theatre to ensure wider understanding of the objectives which 
would have resulted in increased employee buy-in. More time should have been spent to train leaders to become e-literate and not assume that everybody knows technology.

A more humanistic approach, inclusive of understanding human niche theory as opposed to purely transactional approaches for capital gain, is pledged when technological change is initiated. Inadvertently, such an approach will be multidimensional. Of course, this implies that organisational leaders know and understand their employees' diversity. This could create a platform for inclusion, as well as increased meaning and value for individuals and organisations.

This case study illustrated how technology in e-HRM fuels employee isolationism and hampers managing diversity. As employee isolationism increases, employees increasingly feel under threat, reducing productivity. As top-down communication through the hierarchical structure struggles to enable participation, feelings of isolation increase. This can easily become a vicious cycle, furthering employee isolationism and further reducing the potential benefits of diversity.

Given the potential negative impact, future research is required into the effects of technology utilisation on diversity management in diverse cultural settings.

\section{Conclusion}

Our findings provide insight into the surprisingly unintended consequences of diversity and how it affects e-HRM implementation. We also indicated how e-HRM systems can lead to enhanced relational breakdown in a developing country context. Technology should be integrated in managing diversity, as a mechanism of streamlining the e-HRM system and not just focused on operational efficiencies in the 21st century. Such a complimentary approach will enable strategic e-HRM to create value for people and the organisation. If technology is implemented without sensitivity to human diversity, it could result in maladaptive socio-emotional responses and deviations, causing social withdrawal, damage and isolation that diminish the intent of managing diversity.

\section{Acknowledgements Competing interests}

The authors declare that they have no financial or personal relationship(s) that may have inappropriately influenced them in writing this article.

\section{Authors' contributions}

T.B. was the primary researcher. Y.D.P. and H.K. assisted with data analysis and interpretation.

\section{Funding information}

This research received no specific grant from any funding agency in the public, commercial or not-for-profit sectors.

\section{Data availability statement}

Data sharing is not applicable to this article as no new data were created or analysed in this study.

\section{Disclaimer}

The views and opinions expressed in this article are those of the authors and do not necessarily reflect the official policy or position of any affiliated agency of the authors.

\section{References}

Afiouni, F., Karam, C. M., \& El-Haij, H. (2012). The HR value proposition model in the Arab Middle East: Identifying the contours of an Arab Middle Eastern HR model. The International Journal of Human Resource Management, 24(10), 1895-1932. The International Journal of Human Resource Mana
https://doi.org/10.1080/09585192.2012.722559

Alavi, M., Marakas, G. M., \& Yoo, Y. (2002). A comparative study of distributed learning environments on learning outcomes. Information Systems Research, 13(4), 404-415. https://doi.org/10.1287/isre.13.4.404.72

Ball, K. S. (2001). The use of human resource information systems: A survey. Personnel Review, 30, 677-693. https://doi.org/10.1108/EUM0000000005979

Barnes, E., \& Adam, C. (2017). The importance of human resources in a globalised economy: A conceptual framework. Canadian Journal of Applied Science and Technology, 5(2), 134-142.

Barnum, C., \& Wolniansky, N. (1989). Globalization: Moving a step beyond the international firm. Management Review, 78(1), 30-34.

Beck, D. E., \& Cowan, C. C. (1996). Spiral dynamics: Mastering values, leadership and change. Oxford: Blackwell Publishers.

Berg, B. (1998). Content analysis. In B. Berg (Ed.), Qualitative research methods for the social sciences (pp. 233-252). Boston, MA: Allyn \& Bacon.

Bertalanffy, L. V. (1973). General system theory: Foundations, development, applications (Rev. edn.). New York: G. Braziller.

Blom, T. (2015). Fusing organisational change and leadership into a practical roadmap for South-African organisations, Unpublished doctoral thesis, UNISA Graduate School of Business Leadership. Midrand.

Bondarouk, T., Parry, E., \& Furtmueller, E. (2017). Electronic HRM: Four decades of research on adoption and consequences. The International Journal of Human Resource Management, 28(1), 98-131. https://doi.org/10.1080/09585192.2016. 1245672

Bondarouk, T. V., \& Ruël, H. J. M. (2009). Electronic human resource management: Challenges in the digital era. The International Journal of Human Resource Management, 20(3), 505-514. https://doi.org/10.1080/09585190802707235

Bookchin, M. (1980). Toward an ecological society. Montreal: Black Rose.

Boudreau, J. W., \& Ramstad, P. M. (1998). Human resource metrics: Can measures be strategic? Working Paper (pp. 98-10). Ithaca, NY: CAHRS/Cornell University.

Brehm, J. W. (1966). A theory of psychological reactance. New York: Academic Press.

Brehm, J. W. (1972). Responses to loss of freedom: A theory of psychological reactance. Morristown, NJ: General Learning Press.

Brehm, J. W., \& Brehm, S. S. (1981). Psychological reactance: A theory of freedom and control. San Diego, CA: Academic Press.

Briscoe, D. R., Schuler, R. S., \& Claus, L. (2009). International human resource management: Policies and practices for multinational enterprises (3rd edn.). London: Routledge.

Buller, D. B., Borland, R., \& Burgoon, M. (1998). Impact of behavioural intention on effectiveness of message features: Evidence from the family sun safety project. Human Communication Research, 24, 433-453. https://doi.org/10.1111/j.14682958.1998.tb00424.x

Bunker, D., Levine, L., \& Woody, C. (2013). Repertoires of collaboration for disaster management: negotiating emergent and dynamic systems success. In Proceedings of Grand Successes and Failures in IT IFIP WG8.6 Working Conference Bangalore, India, 27-29 June.

Chapman, D. S., \& Webster, J. (2003). The use of technologies in the recruiting, screening, and selection processes for job candidates. International Journal of Selection and Assessment, 11(2-3), 113-120. https://doi.org/10.1111/14682389.00234

Chatterjee, S., Sarker, S., \& Fuller, M. (2009). Ethical information systems development: A Baumanian postmodernist perspective. Journal of the Association for Information Systems, 10(11), Article 3. https://doi.org/10.17705/1jais.00214

Choo, S. S., Halim, H., \& Keng-Howe, I. C. (2010). The impact of globalisation on strategic human resources management: The mediating role of CEO in HR. International Journal of Business Studies, 18(1), 101-124.

Cleveland, J. N., Zinta, S. B., \& Cavanagh, T. (2015). The future of HR is RH: Respect for humanity at work. Human Resource Management Review, 25(2), 146-161. https://doi.org/10.17705/1jais.00214

Cox, T. H. (1993). Cultural diversity in organization: Theory, research and practice. San Francisco, CA: Berrett-Koehler. 
Cummings, T. G., \&Worley, C. G. (2005). Organisation development and change. Mason, $\mathrm{OH}$ : Thomson

Deloitte. (2014). Deloitte report - Global human capital trends 2014: Engaging the 21st century workforce. A Report by Deloitte Consulting LLP and Bersin by Deloitte, Deloitte University Press, Deloitte Touche Tohmatsu Limited, Retrieved from https://www2.deloitte.com/content/dam/Deloitte/ar/Documents/humancapital/arg_hc_global-human-capital-trends-2014_09062014\%20(1).pdf

Dery, K., \& Wailes, N. (2005). Necessary but not sufficient: ERPs and strategic HRM. Strategic Change, 14(5), 265-272. https://doi.org/10.17705/1jais.00214

Doherty, N. F., \& King, M. (2001). An investigation of the factors affecting the successful treatment of organisational issues in systems development projects. European Journal of Information Systems, 10(3), 147-160. https://doi.org/10.1057/palgrave. ejis.3000401

D'Netto, B., Smith, D., Da-Gama-Pinto, C. D. G., \& Australia Department of Immigration and Multicultural Affairs (DIMA). (2000). Diversity management: Benefits, challenges and strategies. NSW: Department of Immigration and Multicultura Affairs. New South Whales.

Dwivedi, Y., Wastell, D., Laumer, S., Henriksen, H., Myers, M., Bunker, D., ... Srivastava, S. (2015). Database: Applied science \& technology source. Information Systems Frontiers, 17(1), 143-157. https://doi.org/10.1007/s10796-014-9500-y

Egan, T. M. (2005). Creativity in the context of team diversity: Team leader perspectives. Advances in Developing Human Resources, 7(2), 207-225. https://doi.org/ 10.1177/1523422305274526

Farndale, E., Paauwe, J., \& Hoeksema, L. (2009). In-sourcing HR: Shared service centres in the Netherlands. The International Journal of Human Resource Management in the Netherlands. The International Journal of Human Reso
20(3), 544-561. https://doi.org/10.1080/09585190802707300

Fitzgerald, B. (1997). The use of systems development methodologies in practice: A field study. Information Systems Journal, 7(3), 201-212. https://doi.org/ 10.1080/09585190802707300

Foster, J. A., Sheridan, P. K., Irish, R., \& Frost, G. S. (2012). Gamification as a strategy for promoting deeper investigation in a reverse engineering activity. Paper presented at the 2012 American Society for Engineering Education Conference, University of Toronto, Toronto, 10 June 2012.

Francis, H., Parkes, C., \& Reddington, M. (2014). E-HR and international HRM: A critical perspective on the discursive framing of e-HR. International Journal of Human Resource Management, 25(10), 1327-1350. https://doi.org/10.1080/09585192.2 013.870309

Garg, P., \& Goel, A. (2016). Emerging issues of human resource management in global context. Jagran Journal of Commerce and Economics, 3(5), 36-42.

Garrett, G. (2000). The causes of globalization. Comparative Political Studies, 33, 941-991.

Gelfand, M. J., Erez, M., \& Aycan, Z. (2007). Cross-cultural organizational behavior Annual Review of Psychology, 58(1), 479-514. https://doi.org/10.1146/annurev. Annual Review of Psycho
psych.58.110405.085559

Gollner, J., Andersen, R, Gollner, K., \& Webster, T. (2015). A study of the usefulness of deploying a questionnaire to identify cultural dynamics potentially affecting a content-management project. IEEE Transactions on Professional Communication, content-management project. IEEE Transactions on Professiona
58(3), 289-308. https://doi.org/10.1109/TPC.2016.2516638

Gorodnichenko, Y., \& Roland, G. (2011). Which dimensions of culture matter for longrun growth? American Economic Review Papers and Proceedings, 101(3), 492-498. https://doi.org/10.1257/aer.101.3.492

Govindarajan, V., \& Gupta, A. K. (2001). The quest for global dominance. San Francisco, CA: Jossey-Bass.

Gowan, M. A. (2012). Employability, well-being, and job satisfaction following a job loss. Journal of Managerial Psychology, 27(8), 780-798. https://doi.org/10.1109/ TPC.2016.2516638

Grant, D., Dery, K., Hall, R., Wailes, N., \& Wiblen, S. (2009, July). Human resource information systems (HRIS): An unrealized potential. Paper presented at the Chartered Institute of Personnel and Development, 2009, Nottingham. Retrieved from http://www.ilera-directory.org/15thworldcongress/files/papers/Track_1/ Wed_W3_DERY.pdf

Graves, C. W. (1974, April). Human nature prepares for a momentous leap, The Futurist, pp. 72-87.

Gueutal, H. G., \& Stone, D. L. (2005). The brave new world of eHR: Human resource management in the digital age. San Francisco, CA: Jossey-Bass.

Haines, V. Y., \& Lafleur, G. (2008). Information technology usage and human resource roles and effectiveness. Human Resource Management, 47(3), 525-540. https:// roles and effectiveness. Hum
doi.org/10.1002/hrm.20230

Harmon, E., Korn, M., Light, A., \& Voida, A. (2016). Designing against the Status Quo. DIS 2016 Companion, June 4 - 8: 65 - 68. Proceedings of the 2016 ACM Conference Companion Publication on Designing Interactive Systems, Brisbane, QLD, Australia. https://doi.org/10.1145/2908805.2913020

Horney, N. (2016). The Gig economy: A disruptor requiring HR agility. People + Strategy: The Professional Journal of HR People and Strategy, 39(3), 20-27.

Hussain, Z., Wallace, J., \& Cornelius, N. E. (2007). The use and impact of human resource information systems on human resource management professionals. Information and Management, 44, 74-89. https://doi.org/10.1016/j.im.2006. 10.006

Ivancevich, J. M., \& Gilbert, J. A. (2000). Diversity management: Time for a new approach. Public Personnel Management, 29(1), 75-92. https://doi.org/10.1177/ 009102600002900106

Ivanov, B., Pfau, M., \& Parker, K. (2009). The attitude base as a moderator of the effectiveness of inoculation strategy. Communication Monographs, 76(1), 47-72. https://doi.org/10.1080/03637750802682471
Jackson, S. E., \& Ruderman, M. N. (1996). Diversity in work teams: Research paradigms for a changing workplace. Washington, DC: American Psychological Association.

Johnson, R. D., \& Brown, K. G. (2017). e-Learning. In G. Hertel, D. Stone, R. D. Johnson, \& J. Passmore (Eds.), The Wiley-Blackwell handbook of the psychology of the internet at work (pp. 369-400). Chichester: Wiley Blackwell.

Johnson, R. D., Lukaszewski, K. M., \& Stone, D. L. (2017). The importance of the interface between humans and computers on the effectiveness of eHRM. Transactions on Human Computer Interaction, 9(1), 23-33. https://doi.org/ 10.17705/1thci.00087

Kaganer, E., Giordano, G. A., Brion, S., \& Tortoriello, M. (2013). Media tablets for mobile learning. Communications of the ACM, 56(11), 68-75. https://doi.org/ 10.1145/2500494

Kavanagh, M. J., Thite, M., \& Johnson, R. D. (2015). Human resource information systems: Basics, applications, and future directions (3rd edn.) Thousand Oaks, CA: Sage.

Kübler-Ross, E. (1963). On death and dying. New York: MacMillan.

Kuhn, P., \& Skuterud, M. (2000). Job search methods: Internet versus traditional. Monthly Labor Review, 123(10), 3-11.

Laubscher, L. (2013). Human niches - Spiral dynamics for Africa, Unpublished doctora thesis, The Da Vinci Institute for Technology Management, Johannesburg.

Lee, W., \& Pfau, M. (1998). The effectiveness of cognitive and affective inoculation appeals in conferring resistance against cognitive and affective attacks. Paper presented at the annual conference of the International Communication Association, Jerusalem, Israel.

Lepak, D. P., \& Snell, S. A. (1998). Virtual HR: Strategic human resource management in the 21st Century. Human Resource Management Review, 8(3), 215-234. https://doi.org/10.1016/S1053-4822(98)90003-1

Lepak, D. P., Bartol, K. M., \& Erhardt, N. L. (2005). A contingency framework for the delivery of HR practices. Human Resource Management Review, 15(2), 139-159. delivery of HR practices. Human Resource $M$
https://doi.org/10.1016/j.hrmr.2005.06.001

Levav, J., \& Zhu, R. (2009). Seeking freedom though variety. Journal of Consumer Research, 36(4), 600-610. https://doi.org/10.1086/599556

Lewin, K. (1951). Defining the field at a given time. In D. Cartwright (Ed.), Field theory in social science (pp. 1-520). New York: Harper \& Brothers.

Loden, M., Rosener, J. B., \& Rosener, J. (1991). Workforce America! Managing diversity as a vital resource. Homewood, IL: Irwin/ Mcgraw Hill.

Marler, J., \& Parry, E. (2016). Human resource management, strategic involvement and e-HRM technology. The International Journal of Human Resource Management,
27(19), 2233-2253. https://doi.org/10.1080/09585192.2015.1091980

Martin, G., \& Reddington, M. (2010). Theorising the links between e-HR and strategic HRM: A model, case illustration and reflections. The International Journal of Human Resource Management, 21(5), 1553-1574. https://doi.org/10.1080/0958 5192.2010.500483

McManus, M. A., \& Ferguson, M. W. (2003). Biodata, personality, and demographic differences of recruits from threes sources. International Journal of Selection and Assessment, 11(2-3), 175-183. https://doi.org/10.1111/1468-2389.00241

Miller, C. H., \& Averbeck, J. M. (in press). Hedonic relevance and outcome relevant involvement. Electronic Journal of Communication, 23(3).

Miller, C. H., Ivanov, B., Sims, J., Compton, J., Harrison, K. J., Parker, K. A., ... Averbeck, J. M. (2013). Boosting the potency of resistance: Combining the motivational forces of inoculation and psychological reactance. Human Communication Research, 39(1), 127-155. https://doi.org/10.1111/j.1468-2958.2012.01438.x

Mor Barak, M. E. (2015). Inclusion is the key to diversity management, but what is inclusion? Human Service Organizations: Management, Leadership \& Governance, 39(2), 83-88. https://doi.org/10.1080/23303131.2015.1035599

Mor Barak, M. E., \& Daya, P. (2014). Fostering inclusion from the inside out to create an inclusive workplace. In B. M. Ferdman \& B. R. Deane (Eds.), Diversity at work: an inclusive workplace. In B. M. Ferdman \& B. R. Deane (Eds.), Diversity
The practice of inclusion (pp. 391-412). San Francisco, CA: Jossey-Bass.

Myers, M. D. (1994). A disaster for everyone to see: An interpretive analysis of a failed is project. Accounting, Management and Information Technologies, 4(4), 185-201. https://doi.org/10.1016/0959-8022(94)90022-1

Naess, A. (1989). Ecology, Community and lifestyle: Outline of an ecosophy. Translated by David Rothenberg. Cambridge: Cambridge University Press.

Neuendorf, K. (2002). The content analysis guidebook. Thousand Oaks, CA: Sage.

Nishii, L. H. (2013). The benefits of climate for inclusion for gender-diverse groups. Academy of Management Journal, 56(6), 1754-1774. https://doi.org/10.5465/ amj.2009.0823

Nishii, L. H., \& Rich, R. E. (2014). Creating inclusive climates in diverse organizations. In B. M. Ferdman \& B. R. Deane (Eds.), Diversity at work: The practice of inclusion (pp. 205-228). San Francisco, CA: Jossey-Bass.

Ogihara, Y., \& Uchida, Y. (2014). Does individualism bring happiness? Negative effects of individualism on interpersonal relationships and happiness. Frontiers in Psychology, 5(135), 1-8. http://doi.org/10.3389/fpsyg.2014.00135

Orlikowski, W. J., \& Robey, D. (1991). Information technology and the structuring of organizations. Information Systems Research, 2(2), 143-169. https://doi.org/ 10.1287/isre.2.2.143

Palmer, C. T., Coe, K., \& Steadman, L. B. (2016). Reconceptualizing the human social niche: How it came to exist and how it is changing. Current Anthropology, 3, 181. https://doi.org/10.1086/685703

Patnayakuni, R. Ruppel, C. P., \& Rai, A. (2006). Managing the complementarity of knowledge integration and process formalization for systems development performance. Journal of the Association for Information Systems, 7(8), 545-567. https://doi.org/10.17705/1jais.00097 
Patton, M. Q. (2015). Qualitative research \& evaluation methods: Integrating theory and practice (4th edn.). Thousand Oaks, CA: Sage Publications.

Pfau, M., Banas, J., Semmler, S. M., Deatrick, L., Lane, L., Mason, A., ... Underhill, J. (2010). Role and impact of involvement and enhanced threat in resistance. Communication Quarterly, 58(1), 1-18. https://doi.org/10.1080/0146337090 3520307

Putnam, R. C., \& Archibald, M. (2016). Specialization and the survival of self-help organizations. Sociological Forum, 31(1), 72. https://doi.org/10.1111/socf.12227

Quick, B. L., \& Stephenson, M. T. (2008). Examining the role of trait reactance and sensation seeking on perceived threat, state reactance, and reactance restoration. Human Communication Research, 34, 448-476. https://doi.org/10.1111/j.14682958.2008.00328.x

Reddington, M., \& Hyde, C. (2008). The impact of e-HR on line managers and employees in the UK: Benefits, problems, and prospects. In M. G. Reddington \& H. Alexande (Eds.), Technology, outsourcing and transforming HR: Potentials, problems, and guidance for practitioners (pp. 35-59). Oxford: Butterworth-Heinemann/Elsevier.

Reilly, P., \& Williams, T. (2003). How to get best value from HR: The shared services option. Gower: Aldershot.

Salas, E., DeRouin, R., \& Littrell, L. (2005). Research based guidelines for distance learning: What we know so far. In H. G. Gueutal \& D. L. Stone (Eds.), The brave new world of eHR: Human resources management in the digital age (pp. 104-137). San Francisco, CA: Jossey Bass.

Samoilenko, S. (2008). Information systems fitness and risk in IS development: Insights and implications from chaos and complex systems theories. Information System Frontiers, 10(3), 281-292. https://doi.org/10.1007/s10796-008-9078-3

Senior, B., \& Swailes, S. (2010). Organisational change. Harlow: Pearson Education.

Sherer, S., Kohli, R., \& Baron, A. (2003). Complementary investment in change management and it investment payoff. Information Systems Frontiers, 5(3), 321-333. https://doi.org/10.1023/A:1025609613076

Sitzmann, T., Kraiger, K., Stewart, D., \& Wisher, R. (2006). The comparative effectiveness of Web-based and classroom instruction: A meta-analysis. Personnel Psychology, 59(3), 623-664. https://doi.org/10.1111/j.1744-6570.2006.00049.x

Smale, A., \& Heikkilä, J. P. (2009). IT-Based integration of HRM in a foreign MNC subsidiary: A micro-political perspective. In T. Bondarouk, H. Ruel, K. GuiderdoniJourdain, \& E. Oiry (Eds.), Handbook of research on e-transformation and human resources management technologies: Organizational outcomes and challenges, (pp. 153-170). Hershey, PA: IGI Global. https://doi.org/10.4018/978-1-60566304-3.ch009

Spencer, D. (2017). Work in and beyond the Second Machine Age: The politics of production and digital technologies. Work, Employment and Society, 31(1), 142-152. https://doi.org/10.1177/0950017016645716

Stahl, G., Mendenhall, M. E., \& Oddou, G. R. (2012). Readings and cases in internationa human resource management and organizational behavior (5th edn.). London: Routledge.
Stebbins, M. W. (1989). Downsizing with 'Mafia Model' consultants. Business Forum, $45,45-47$.

Stone, D. L., \& Deadrick, D. L. (2015). Challenges and opportunities affecting the future of human resource management. Human Resource Management Review, 25(2), 139-145. https://doi.org/10.1016/j.hrmr.2015.01.003

Stone, D. L., Deadrick, D. L., Lukaszewski, K. M., \& Johnson, R. (2015). The influence of technology on the future of human resource management. Human Resource Management Review, 25(2), 216-231. https://doi.org/10.1016/j.hrmr.2015.01.002

Strohmeier, S. (2007). Research in e-HRM: Review and implications. Human Resource Management Review, 17, 19-37. https://doi.org/10.1016/j.hrmr.2006.11.002

Sykes, T. A. (2015). Support structures and their impacts on employee outcomes: A longitudinal field study of an enterprise system implementation. MIS Quarterly, 39(2), 473-495. https://doi.org/10.25300/MISQ/2015/39.2.09

Tansley, C., Newell, S., \& Williams, H. (2001). Effecting HRM-style practices through an integrated human resource information system. Personnel Review, 30(3), 351-371. https://doi.org/10.1108/00483480110385870

Thoumrungroje, P., \& Tansuhaj, P. (2004). Globalization effects, co-marketing alliances and performance. Journal of American Academy of Business, Cambridge, 5(1/2), 495-502.

Truex, D., Baskerville, R., \& Travis, J. (2000). Amethodical systems development: The deferred meaning of systems development methods. Accounting, Management and Information Technologies, 10(1), 53-79. https://doi.org/10.1016/S09598022(99)00009-0

Van Dyk, G., \& De Kock, F. (2004). The relevance of the individualism - Collectivism (IC) factor for the management of diversity in the South African national defence force. SA Journal of Industrial Psychology, 30(2), 90-95. https://doi.org/10.4102/ sajip.v30i2.15

Varey, R. J., Wood-Harper, T., \& Wood, B. (2002). A theoretical review of management and information systems using a critical communications theory. Journal of Information Technology (Routledge, Ltd.), 17, 229-239. https://doi.org/10.1080/0 268396022000017725

Wan, D., Kok, V., \& Ong, C. H. (2002). Strategic human resource management and organizational performance in Singapore. Sage Publication, 34, 33-42. https:// doi.org/10.1177/0886368702034004006

Wicklund, R. A. (1974). Freedom and reactance. Potomac, MD: Lawrence Erlbaum.

Wynekoop, J. L., \& Russo, N. L. (1995). Systems development methodologies: Unanswered questions. Journal of Information Technology, 10(2), 65-73. https:// doi.org/10.1177/0886368702034004006

Zanoni, P. (2011). Diversity in the lean automobile factory: Doing class through gender disability and age. Organization, 18(1), 105-127. https://doi.org/10.1177/1350 508410378216

Zusman, R. R., \& Landis, R. S. (2002). Applicant preferences for web-based versus traditional job postings. Computer in Human Behavior, 18(3), 285-296. https:// doi.org/10.1016/S0747-5632(01)00046-2 